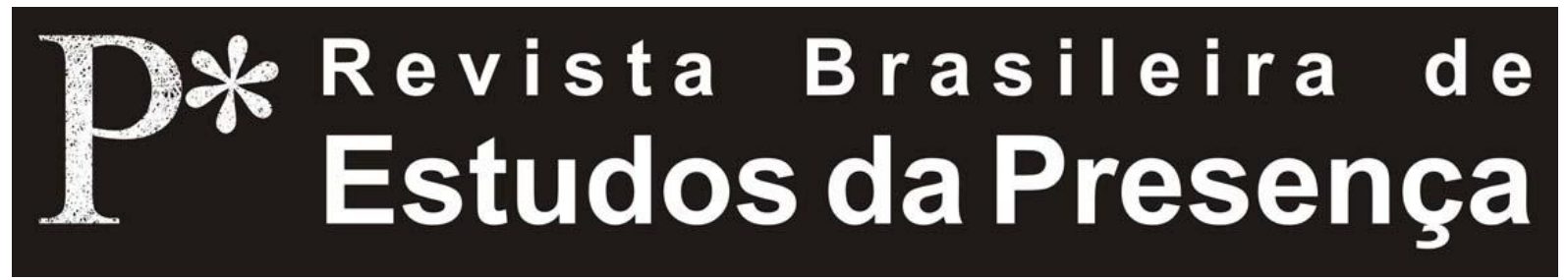

DOI - http://dx.doi.org/10.1590/2237-266022791

ISSN 2237-2660

\title{
O Pulo do Gato ou Reflexões sobre a Presença do Ator
}

\author{
Inês Alcaraz Marocco \\ Elisa Heidrich \\ Kalisy Cabeda \\ Philipe Philippsen \\ Rodrigo Fiatt
}

Universidade Federal do Rio Grande do Sul - UFRGS

RESUMO - O Pulo do Gato ou Reflexões sobre a Presença do Ator - Este artigo tece reflexões sobre o desenvolvimento da presença física do ator através de um trabalho pré- expressivo com a técnica da Máscara Neutra, segundo o sistema pedagógico de Jacques Lecoq, numa experiência acadêmico/artística com alunos do curso de Teatro da Universidade Federal do Rio Grande do Sul durante o processo de criação do espetáculo $O$ Sobrado.

Palavras-chave: A Arte do Ator. Jacques Lecoq. $O$ Sobrado (espetáculo). Pré- expressividade. Máscara Neutra.

\begin{abstract}
The Leap of the Cat or Reflexions on the Actor's Presence - This article intertwines reflexions on the development of the actor's physical presence through a pre-expressive work with the Neuter Mask, according to the pedagogic system of Jacques Lecoq, in an academical artistic experiment with undergraduates from the Theater course at Federal University of Rio Grande do Sul during the creation of the play $O$ Sobrado.

Keywords: The Art of the Actor. Jacques Lecoq. $O$ Sobrado (play). Pre-expressivity. Neuter Mask.

RÉSUMÉ - Le Bond du Chat ou des Réflexions sur la Présence Physique de l'Acteur - Cet article tisse des réflexions sur le développement de la présence physique de l'acteur à partir d’un travail pré expressif par la technique du Masque Neutre, suivant le
\end{abstract}

Inês Alcaraz Marocco, Elisa Heidrich, Kalisy Cabeda, Philipe Philippsen, Rodrigo Fiatt, O Pulo do Gato ou Reflexões sobre a Presença do Ator

R.bras.est.pres., Porto Alegre, v.1, n.2, p. 312-330, jul./dez., 2011.

Disponível em http://www.seer.ufrgs.br/presenca 
système pédagogique de Jacques Lecoq, dans une expérience academique/artistique avec des étudiants du Cursus Théâtre à l'Université Fédérale du Rio Grande do Sul, pendant le processus de création du spectacle $O$ Sobrado.

Mots-clés: L'Art de l'Acteur. Jacques Lecoq. $O$ Sobrado (spectacle). Pre expressivité. Masque Neutre.

Não foram poucas as vezes em que artistas, pedagogos, pesquisadores, atores, bailarinos, diretores, antropólogos, e todos aqueles que se interessam pelo estudo das artes vivas (Stanislavski, Decroux, Barba, Turner, Lecoq, Cardona, Oida, Siegfried, entre muitos outros) perceberam no comportamento dos animais elementos importantes para conseguir realizar performances utilizando-se desse para alcançar seus objetivos. Yoshi Oida relata, no seu livro $O$ Ator errante (1999), o primeiro exercício que Peter Brook solicitou ao grupo internacional de atores, o C.I.R.T. (Centro Internacional de Pesquisas Teatrais), que foi o de visitar o zoológico. Após a visita, Brook disse:

Os animais são cheios de graça em seus movimentos, pois seus corpos estão liberados de qualquer tensão. Mas, ao mesmo tempo, não estão em estado de repouso: estão sempre prontos para se movimentar, repentinamente, seja para escapar de uma agressão, seja para agarrar uma presa. Os animais mantêm-se em dois estados psíquicos ao mesmo tempo. Seus corpos estão livres e bem equilibrados, seus espíritos conscientes e concentrados. Em consequência, o animal reage rapidamente, pode tomar qualquer direção, deslocar-se com movimentos enérgicos ou com uma precisão delicada. Isso ilustra exatamente qual deve ser a atitude fundamental do ator em cena (Oida, 1999, p. 58).

Nesta linha de pensamento, alguns artistas pedagogos se inspiraram no comportamento dos animais para contribuir na formação de atores/dançarinos. Se observamos o gato brincando, inventando sempre novas possibilidades de jogo e reagindo com movimentos acrobáticos e arriscados, percebemos que eles são experts em realizar os princípios do jogo teatral não só a nível físico, mas também imaginativo. A atitude de alerta, por exemplo, tão comum nos animais, é um dos estados de tensão mais requisitados no trabalho do ator/dançarino e

Inês Alcaraz Marocco, Elisa Heidrich, Kalisy Cabeda, Philipe Philippsen, Rodrigo Fiatt, O Pulo do Gato ou Reflexões sobre a Presença do Ator

R.bras.est.pres., Porto Alegre, v.1, n.2, p. 312-330, jul./dez., 2011.

Disponível em http://www.seer.ufrgs.br/presenca 
essencial para a concretização do jogo. Para melhor exemplificar o que acabamos de expor, citamos o comentário da jornalista e coreógrafa Patricia Cardona $(1999$, p. 4) sobre as razões de utilizar o comportamento animal para passar conceitos operacionais sobre as artes cênicas ao corpo do bailarino/ator.

Esta terminologia não só reduz o número de confusões na transmissão do ensino como acelera o processo de aprendizagem. Impede, além disso, a especulação gratuita e a retórica impenetrável de muitos investigadores das artes cênicas. Pretendo, juntamente, chamar as coisas pelo seu próprio nome para aproximar o pensamento à ação, para materializar a ideia sem risco de perdermos a criatividade ao lado do vocábulo acadêmico, tão afastado do processo vital e orgânico do bailarino/ator.

$\mathrm{Na}$ realidade, além de inspirar o futuro ator/dançarino na realização do jogo, a atitude do gato é muito importante para demonstrar a importância da autonomia imaginativa no trabalho artístico que se desenvolve aos saltos, que não segue uma sequência, que faz diferentes relações, que anda para frente e para trás e não de uma forma logicamente cronológica. Outro aspecto relevante, a que nos remete este exemplo do gato, é a questão da importância da animalidade no trabalho do ator. Sob a perspectiva da Etnocenologia ${ }^{1}$, encontramos em Pradier (1990, p. 93-94) a afirmação de que atores e dançarinos são restauradores biológicos.

[...] um ator/dançarino/cantor é um animal restaurado e em restauração (Pradier, 1986 apud Pradier, 1990, p. 93-94). Aqui restaurado não tem o significado dado por Richard Schechner em sua teoria, muito interessante, sobre a "restauração do comportamento" (Schechner, 1985, p. 35 apud Pradier, 1990, p. 93-94). Eu desejo, apenas assinalar uma "restauração biológica" oposta à "decadência biológica”, observada na vida diária de muitas culturas.

A arte do espetáculo é uma arte viva e, para Pradier, que segue a linha biocultural na condução de suas pesquisas, deveríamos levar em conta os fundamentos biológicos das manifestações espetaculares, se quisermos restaurar esse aspecto fundamental $\mathrm{e}$ essencial dessa área de conhecimento.

Inês Alcaraz Marocco, Elisa Heidrich, Kalisy Cabeda, Philipe Philippsen, Rodrigo Fiatt, O Pulo do Gato ou Reflexões sobre a Presença do Ator

R.bras.est.pres., Porto Alegre, v.1, n.2, p. 312-330, jul./dez., 2011.

Disponível em http://www.seer.ufrgs.br/presenca 
Neste sentido, foram os etologistas ${ }^{2}$ os primeiros a chamar a atenção sobre o enraizamento biológico das práticas culturais, performáticas (Pradier, 2000), através dos diferentes rituais que eles desenvolvem com funções desde a sobrevivência, a comunicação entre espécies e entre seus pares até a sedução e a continuação da espécie através da realização do ato sexual. Da mesma forma que os animais, o homem também performa, ao desenvolver esses mesmos rituais, dos quais nem se dá mais conta, de tão arraigados e inconscientes que estão. Indo mais a fundo nesta questão do vínculo entre os rituais e os seus fundamentos biológicos, foi graças às pesquisas desenvolvidas pelo antropólogo Victor Turner que essa conexão pode ser efetivada. Ao se deparar com os progressos da genética, neurologia e etologia ele resolveu ampliar a relação da ritualização animal com o nosso corpo e psique humanos. Para isso, ele se apoiou nas descobertas do neuroanatomista Paul McLean (Turner, 1987/88), sobre o que ele denominou cérebro três em um (triuno), concluindo pela existência do que pode ser chamado de estruturas arcaicas do cérebro humano. Nelas, ele investigou o chamado sistema límbico, “[...] uma antiga parte do cérebro, que evoluiu e que diz respeito às emoções, situada dentro ou nos limites do córtex" (Turner, 1987/88, p. 160-161). Este cientista descobriu que o cérebro evoluiu em três estágios (cérebro três em um) desenvolvendo partes que continuam ativamente conosco, ainda que modificadas e se intercomunicando: o cérebro réptil (comportamento instintivo, corrente do movimento), o paleo mammalian ou o velho cérebro mamífero (corrente das emoções) e o neo mamífero ou cérebro mamífero novo (corrente de pensamento). A partir desses dados podemos perceber que os dois primeiros apresentam características que tocam de perto aqueles que se interessam pela prática do fazer teatral. Assim sendo, é importante não só a consciência destes aspectos, mas também o seu resgate e restauração para que seja possível a realização de uma arte que transcenda e seja essencial. Como proceder a este resgate?

Entendemos que é na fase da infância que as capacidades relacionadas aos dois primeiros cérebros

Inês Alcaraz Marocco, Elisa Heidrich, Kalisy Cabeda, Philipe Philippsen, Rodrigo Fiatt, O Pulo do Gato ou Reflexões sobre a Presença do Ator

R.bras.est.pres., Porto Alegre, v.1, n.2, p. 312-330, jul./dez., 2011.

Disponível em http://www.seer.ufrgs.br/presenca 
citados, como a imaginação, a intuição, a emoção, entre outras, estão mais emergentes e presentes. Nesta fase da vida agimos como pequenos animais, com nossas percepções aguçadas, com nossa imaginação e intuição afloradas e sem medo de agir, arriscar, e tudo isso fazemos com prazer. É nesse momento que apresentamos uma plenitude em todos os sentidos que são vitais para o campo da representação atoral. Isso é verificável quando vemos uma criança brincando, onde ela se expressa de forma orgânica e inteira. Da mesma forma quando vemos um animal em cena, não tiramos os olhos dele. Que atração ele exerce sobre o nosso olhar que faz com que só enxerguemos a sua presença em detrimento da do ator?

Ariane Mnouchkine (apud Féral, 2001, p. 44), diretora teatral e cineasta francesa, comenta que $o$ verdadeiro ator deve ter uma criança dentro dele e que deve acioná-la no trabalho de criação, "[...] eu acredito que tem alguma coisa no trabalho do ator que faz com que este último não arremede a infância, mas entre nela, despojando-se das imagens feitas que são o contrário da imaginação".

Como desenvolver esta presença, no caso do homem adulto recuperando esse estado animal, tão desenvolvido na infância e que agora se encontra embotado por nossas carapaças e vícios corporais e mentais? Como resgatar esses aspectos no ator adulto? Como desenvolver esse trabalho de resgate no ator ocidental que aprende a atuar depois de certa idade, ao contrário da cultura oriental, onde $\mathrm{o}$ ator inicia sua aprendizagem com um mestre na infância? Como restaurar a animalidade do ator? Como desenvolver o estado de infância no ator?

Se analisarmos o gato no seu comportamento natural de jogo perceberemos, além da flexibilidade e disponibilidade corporal, que o bichano explora diferentes tipos de energia e cria constantemente novas possibilidades de jogar. Se transpormos para o trabalho de atuação, como faríamos para desenvolver esses elementos no comportamento do ator? É provável que eles seriam desenvolvidos de forma eficaz através de um trabalho pré-expressivo, além de um outro que explorasse a capacidade da imaginação e as qualidades das energias.

Inês Alcaraz Marocco, Elisa Heidrich, Kalisy Cabeda, Philipe Philippsen, Rodrigo Fiatt, O Pulo do Gato ou Reflexões sobre a Presença do Ator

R.bras.est.pres., Porto Alegre, v.1, n.2, p. 312-330, jul./dez., 2011.

Disponível em http://www.seer.ufrgs.br/presenca 
Confirmando essa linha de pensamento, encontramos em E. Barba (apud Pradier, 1987, p. 43) duas noções operatórias que nos auxiliarão, neste trabalho, a sistematizar teoricamente o desenvolvimento da presença do ator/dançarino: o trabalho pré-expressivo e a energia. Acrescentaríamos aqui a noção de imaginação, por acreditarmos como A. Mnouchkine (apud Féral, 2001, p. 43) que se o ator quer estar presente, é fundamental que ele trabalhe o músculo da imaginação.

Não são todos os pesquisadores e praticantes da arte teatral que se utilizam da palavra presença para definir a capacidade do ator de irradiar em cena, atraindo os olhares do público. Na realidade, todos os atores estão presentes, a diferença se encontraria na qualidade desta presença. Citaremos a seguir alguns relatos de alguns artistas, atores e diretores pedagogos sobre seus procedimentos para alcançar esta qualidade que diferencia os atores. Leabhart (1994, p. 12) comenta como Decroux conseguiu atingir a presença teatral, através do trabalho com a máscara

Os exercicios de máscara no Vieux Colombier ensinaram a Decroux como o corpo desnudado deveria mover-se para alcançar a máxima visibilidade e impacto no palco vazio de Copeau. As linhas arquitetônicas que Decroux construiu no corpo telegrafaram uma visibilidade ampliada e formaram uma superfície na qual o ator podia espalhar as cores de diferentes qualidades dinâmicas. E o corpo desnudado sobre o palco nu resplandecia com luz interior quando o ator era capaz de "esvaziar o apartamento" e "Deus vinha morar ali”.

Brook (2000, p. 12) nos conta a sua técnica de estimular $o$ ator a jogar de forma mais intensa e viva.

Em nosso trabalho costumamos usar um tapete como zona de ensaio, com um objetivo muito claro: fora do tapete, o ator está na vida cotidiana, pode fazer o que quiser: desperdiçar a energia, fazer movimentos que não expressam nada em particular, coçar a cabeça, tirar um cochilo...Mas assim que pisa no tapete está obrigado a ter uma intenção definida, a estar intensamente vivo, pela simples razão de que há um publico observando.

Oida (1999, p. 49), percebe que

Inês Alcaraz Marocco, Elisa Heidrich, Kalisy Cabeda, Philipe Philippsen, Rodrigo Fiatt, O Pulo do Gato ou Reflexões sobre a Presença do Ator

R.bras.est.pres., Porto Alegre, v.1, n.2, p. 312-330, jul./dez., 2011.

Disponível em http://www.seer.ufrgs.br/presenca 
[...] uma boa interpretação teatral é mais ou menos o equivalente a uma prática zen, como havia assinalado o primeiro grande mestre do teatro nô, Zeami (que viveu e escreveu sobre teatro no final do século XIV e início do século XV): "Quando nos concentramos corretamente, atingimos um estado em que podemos voar".

Mnouchkine (apud Féral, 2001, p. 43), por exemplo, não faz menção à expressão presença para os seus atores, mas comenta sobre os estados de estar presente, ser presente.

A presença é na realidade alguma coisa que constatamos, mas eu nunca trabalhei com esta noção. Eu não saberia dizer a um ator que fosse presente. No entanto, o que eu sei, o que eu tento fazer com o ator, é que ele esteja no presente, na sua ação, na sua emoção, no seu estado e na versatilidade da vida também [...] A presença progride com a capacidade de nudez de um ator.

Percebemos que todos esses artistas fazem referências ao desenvolvimento de capacidades que são contempladas pela técnica da Máscara Neutra ${ }^{3}$ : a nudez, a calma, o estar vivo em cena, e o estado de transcender, voar. Constatamos também, que essas características equivalem aos atributos apresentados nas noções operatórias que definem a presença física, as quais nos propusemos a trabalhar aqui: pré-expressividade, energia e imaginação. Desde o uso da própria técnica da Máscara Neutra (por Decroux) aos trabalhos desenvolvidos por Brook, Oida e Mnouchkine, todos fazem menção à questão da calma, da neutralidade, ou nudez do ator assim como do trabalho sobre as energias e imaginação. Ao mencionar a nudez do ator como fundamental para o estar presente, eles estão se referindo à capacidade de entrega do ator ao trabalho que um treinamento pré-expressivo, como a técnica da Máscara Neutra pode ajudar a desenvolver. Mnouchkine, ao citar a expressão estar no presente, se refere ao estado de jogo no aquilagora, requisito fundamental no desenvolvimento da imaginação. Na realidade, é muito dificil separar a préexpressividade, da energia e da imaginação, pois eles se imbricam naturalmente no trabalho com a máscara.

Inês Alcaraz Marocco, Elisa Heidrich, Kalisy Cabeda, Philipe Philippsen, Rodrigo Fiatt, O Pulo do Gato ou Reflexões sobre a Presença do Ator

R.bras.est.pres., Porto Alegre, v.1, n.2, p. 312-330, jul./dez., 2011.

Disponível em http://www.seer.ufrgs.br/presenca 
Encontramos apoio em Nicola Savarese (apud Féral, 1993, p. 127) quando ele se refere à presença como um estado que implica também no desenvolvimento da energia. "Presença cênica e energia são duas maneiras de nomear a mesma coisa: não ser entediante aos olhos do espectador". De fato, uma coisa não vai sem a outra, pois a energia não é um potencial adquirido, é uma capacidade desenvolvida, que se aprende para a cena, e isso só se consegue com um trabalho de controle e domínio através de um trabalho pré-expressivo (Féral, 1993, p.127).

Dentro dessa perspectiva, da presença do ator que compreende as noções operatórias lançadas: préexpressivo, energia e imaginação, relataremos a seguir uma experiência de criação artística desenvolvida por um grupo de alunos do Departamento de Arte Dramática do Instituto de Artes da Universidade Federal do Rio Grande do Sul que resultou no espetáculo $O$ Sobrado, no ano de 2008. É importante ressaltar que, durante todo o processo de criação, as três noções operatórias aparecem de forma mesclada e intercalada, jamais separadas. Se as citamos isoladamente é para exemplificar e enfatizar o que estamos nos propondo a comprovar, pois na realidade elas nunca aconteciam sozinhas, foram interdependentes durante todo o processo.

Este espetáculo foi uma adaptação cênica de $O$ Continente, primeira parte da Trilogia $O$ Tempo e o Vento, de Erico Verissimo. Em $O$ Sobrado a ação se passa em 1895, quando o chefe político republicano Licurgo Cambará se encontra sitiado em sua casa, junto à sua família e correligionários, sob o cerco de tropas federalistas. Fechados no sobrado durante dez dias, com pouca comida, água e munição, os personagens da trama relacionam-se em um meio perturbado e agonizante, enquanto a morte se faz presente dentro e fora da casa. Nesse ambiente angustiante, Licurgo resiste à invasão dos maragatos $\mathrm{e}$, intolerante, se recusa a pedir trégua aos inimigos. Permeiam nessa obra-prima da literatura gaúcha o patriarcalismo, o belicismo e a relação com a terra.

Inês Alcaraz Marocco, Elisa Heidrich, Kalisy Cabeda, Philipe Philippsen, Rodrigo Fiatt, O Pulo do Gato ou Reflexões sobre a Presença do Ator

R.bras.est.pres., Porto Alegre, v.1, n.2, p. 312-330, jul./dez., 2011.

Disponível em http://www.seer.ufrgs.br/presenca 


\section{A Máscara Neutra: pré-expressividade, energia e imaginação}

Partindo do pressuposto de que a técnica da Máscara Neutra contempla as funções de desenvolver a pré-expressividade, as capacidades de imaginação e as qualidades de energia no trabalho do ator, relataremos a experiência desenvolvida neste processo de criação artística.

Ao estudar os capítulos de O Sobrado percebemos uma atmosfera dramática de uma densidade importante, além de muitos personagens masculinos e em sua maioria de idade avançada, exatamente o contrário do material humano que tínhamos no grupo escolhido: na maioria jovens e mulheres. A Prof ${ }^{a} \operatorname{Dr}^{a}$ Maria da Glória Bordini, uma das maiores pesquisadoras da obra de Erico Verissimo encontrou-se com o grupo numa fase inicial do trabalho a fim de esclarecer alguns pontos importantes do autor e do romance com o qual iríamos trabalhar. Seu maior questionamento sobre o trabalho foi justamente este: como poderíamos adaptar $O$ Sobrado com um elenco composto majoritariamente de jovens e mulheres? Precisávamos de um trabalho eficiente, que nos capacitasse a transpor $O$ Sobrado para a cena resgatando a mesma atmosfera dramática criada por Erico.

A nossa ideia, no início do processo, era a de formatar, nivelar o grupo, de torná-lo coeso e, ao mesmo tempo, instrumentalizá-lo num trabalho pré-expressivo, de modo a possibilitar aos atores experimentar e concretizar em seus corpos diferentes qualidades de energia e atmosferas. Neste sentido, pensamos que a utilização da técnica da Máscara Neutra seria o ideal. Ao iniciarmos então o processo de aprendizagem da Máscara Neutra, que além de funcionar como técnica préexpressiva, limpando os atores de seus vícios e clichés, disponibilizando-os para o jogo, percebemos que ela era perfeita para o desenvolvimento do clima e atmosfera mais dramáticos do romance. Essa técnica, criada por Jacques Copeau na França, é ainda hoje utilizada por Jacques Lecoq (2010) na sua Escola Internacional de Teatro, Mimo e Movimento, onde é a base do seu sistema pedagógico.

Inês Alcaraz Marocco, Elisa Heidrich, Kalisy Cabeda, Philipe Philippsen, Rodrigo Fiatt, O Pulo do Gato ou Reflexões sobre a Presença do Ator

R.bras.est.pres., Porto Alegre, v.1, n.2, p. 312-330, jul./dez., 2011.

Disponível em http://www.seer.ufrgs.br/presenca 
A Máscara Neutra desenvolve, essencialmente, a presença do ator no espaço que o envolve. Ela o coloca em estado de descoberta, de abertura, de disponibilidade para receber, permitindo que ele olhe, ouça, sinta, toque coisas elementares, no frescor de uma primeira vez (Lecoq, 2010, p. 71).

Além disso, o uso da Máscara potencializou nos atores o estado de jogo, acionando o imaginário e as diferentes energias. Ao desenvolver o aspecto do vazio, que poderíamos associar ao estado de silêncio, calma e tranquilidade que propõe Lecoq, o ator se predispõe a um tipo de jogo diferente. Ele deve ser e estar sendo, transcender o cotidiano, o que implica em risco, porque é do nível do desconhecido e, assim, colocando aquele que porta a máscara, da mesma forma que no jogo, sempre à beira do precipício. Leabhart (1994) comenta uma carta escrita por Jean Dasté em 1994, sobre o uso da máscara:

Antes de cada exercício tínhamos que nos preparar, criar em nós mesmos uma espécie de vazio para poder permitir que uma outra individualidade tomasse vida. Descobri, ao mudar de rosto, que não era mais meu "eu" usual, cotidiano. Era como se possuído por um outro, e este outro existia em uma dimensão que não era a minha. E que o exercício que eu tentava expressar comandava meu corpo para que fizesse outros gestos, atitudes diferentes (Leabhart, 1994, p. 8).

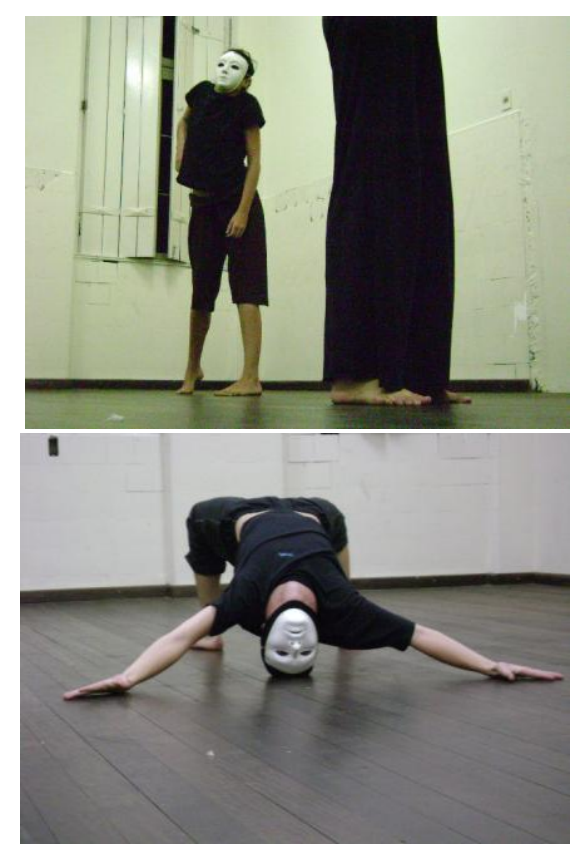

Figuras 1 e 2 - Exercícios com a Máscara Neutra (Foto do Grupo)

Inês Alcaraz Marocco, Elisa Heidrich, Kalisy Cabeda, Philipe Philippsen, Rodrigo Fiatt, O Pulo do Gato ou Reflexões sobre a Presença do Ator

R.bras.est.pres., Porto Alegre, v.1, n.2, p. 312-330, jul./dez., 2011.

Disponível em http://www.seer.ufrgs.br/presenca 
Dessa forma, buscamos, através da máscara, despertar nos atores o estado essencial, orgânico, o mesmo que encontramos no jogo do animal e da criança, já referidos na primeira parte deste texto, e que é tão fundamental para $\mathrm{o}$ ator. Neste mesmo sentido, aprofundando ainda mais o trabalho com a máscara, e enfatizando o desenvolvimento da imaginação e das diferentes energias do ator, utilizamos como estímulos os elementos da natureza, assim como a sua transposição. A utilização dos elementos da natureza, que visa o desenvolvimento de um corpo expressivo, para dar vida à máscara que é neutra, foi fundamental para a criação do espetáculo. Além disso, a sua utilização no trabalho do ator é importante para que ele tome consciência de que, da mesma forma que o aspecto da animalidade faz parte do nosso ser, a terra, a água, o ar e o fogo também nos constituem e que, se quisermos atuar, viver a vida de personagens, devemos considerar que eles são seres humanos e, como tais, habitados por diferentes elementos biográficos, animais, materiais, minerais entre outros. Para Lecoq (2010, p. 79),

[...] a metodologia das transferências, que consiste em apoiar-se na dinâmica da natureza, dos gestos de ação, dos animais, das matérias, para, daí, servir a finalidades expressivas, com o intuito de interpretar melhor a natureza humana. A meta é atingir um nível de transposição teatral, fora da interpretação realista.

Com a técnica da transposição dos elementos da natureza, o processo de composição e criação dos personagens foi mais eficaz, o que também refletiu nas atmosferas e climas das cenas. Com esses estímulos concretos tornou-se possível a materialização da densidade dramática dos personagens e das situações do romance, possibilitando uma via direta na apropriação e transposição do texto literário para a cena. De modo geral, na criação e composição de seus personagens, os atores transitaram por todos os elementos da natureza, mesclando-os, de modo que no resultado final foi difícil discerni-los. Com esse trabalho, criamos uma linguagem em comum no grupo, onde, ao recebermos estímulos dos elementos água, terra, ar e fogo, automaticamente os

Inês Alcaraz Marocco, Elisa Heidrich, Kalisy Cabeda, Philipe Philippsen, Rodrigo Fiatt, O Pulo do Gato ou Reflexões sobre a Presença do Ator

R.bras.est.pres., Porto Alegre, v.1, n.2, p. 312-330, jul./dez., 2011.

Disponível em http://www.seer.ufrgs.br/presenca 
fisicalizávamos, acionando, dessa forma, diferentes estados e paixões, o que contrapunha a ilustração de sentimentos humanos. Em alguns momentos do processo, fomos estimulados pela diretora a trazer a imagem do fogo, da terra ou de outro elemento qualquer para a ação do personagem ou a situação fictícia em que esse se encontrava.

Algumas cenas, por exemplo, foram criadas estritamente a partir do estímulo do elemento, antes mesmo das ações dos personagens. Numa primeira abordagem, fisicalizávamos os elementos fazendo uma transposição crua para as cenas, era quase uma demonstração do elemento, como o grupo estava acostumado a realizar durante o treinamento com a máscara. Mas, nos ensaios e com a apropriação, pelos atores, das circunstâncias propostas das situações no romance, os elementos foram sendo transpostos em acordo com as ações dos personagens e o clima e a atmosfera da situação. A imagem do elemento permanece, porém, como um estímulo anterior à ação, modificando-a objetivamente e de forma eficaz, permitindo aos atores jogar de forma autônoma e orgânica. O que o público vê é o resultado da soma do estímulo do elemento com a ação do ator, trazendo uma qualidade à ação, diferente do sistema que parte da referência psicológica que resultaria na ilustração do sentimento e não na sua corporificação mais orgânica.

Tomemos a cena do flashback, intulada Bolivar $e$ Luzia, situação em que os personagens Bolívar e Luzia voltam de uma viagem a Porto Alegre e, ao chegarem em casa, descobrem que o seu filho, o Licurgo, foi colocado por Bibiana na água furtada, fechado a chave, para impedir o contato com os pais que vinham da capital, contaminada pela peste. Esta cena foi trabalhada da seguinte forma: a assistente de direção indicou um elemento da natureza para cada personagem, Bibiana seria a Terra, pela impassividade demonstrada por ela na cena e pela posição oposta à de Luzia; Bolívar seria o Fogo, pela raiva com que ele reprime sua esposa e que libera ao final da cena, terminando por espancá-la e Luzia seria o Vento, justamente por sua força na cena e o

Inês Alcaraz Marocco, Elisa Heidrich, Kalisy Cabeda, Philipe Philippsen, Rodrigo Fiatt, O Pulo do Gato ou Reflexões sobre a Presença do Ator

R.bras.est.pres., Porto Alegre, v.1, n.2, p. 312-330, jul./dez., 2011.

Disponível em http://www.seer.ufrgs.br/presenca 
efeito que tem de aumentar a raiva de Bolívar em oposição a Bibiana, que o acalma.

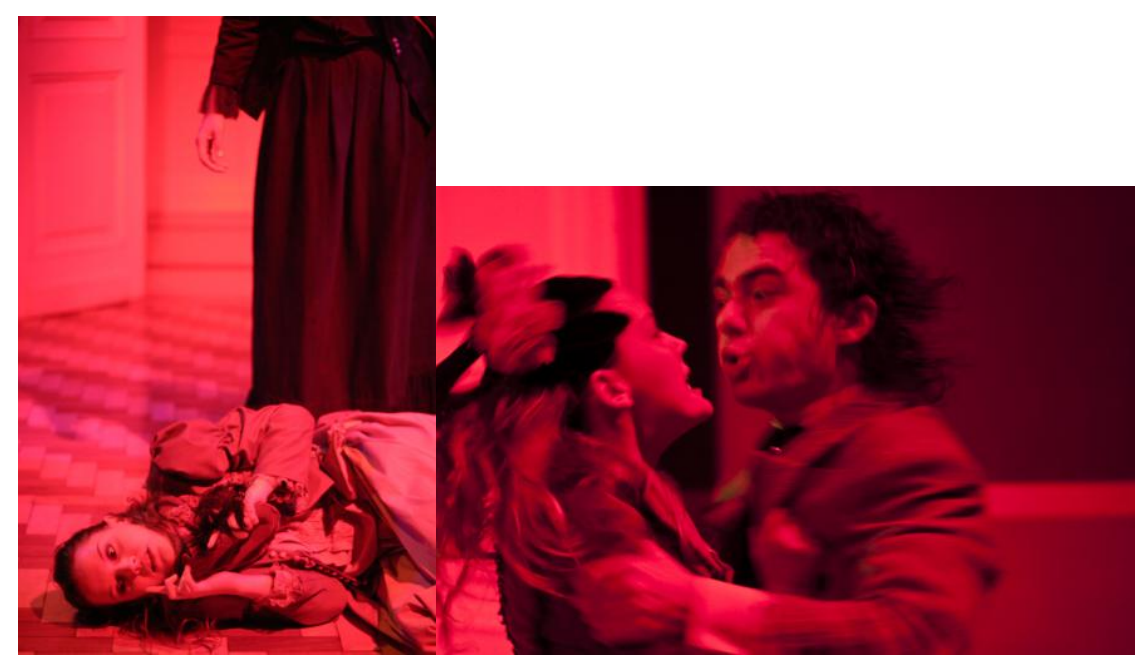

Figuras 3 e 4 - Cena de Bolívar e Luzia (Foto Felipe Ramalho)

Outro exemplo desse mesmo tipo de trabalho aconteceu em uma das cenas onde acontece o velório da criança que nasceu morta (filha do personagem Licurgo Cambará). Para concretizar essa situação utilizamos a transposição do elemento Terra para o corpo dos atores, desenvolvendo a densidade necessária, criando a situação sem psicologismos, priorizando o estado e as tensões corporais. Através desse trabalho o público compreende de forma visível, através do corpo do ator, a situação vivida pelo personagem, pois visualizam as suas sensações internas, agora externalizadas.

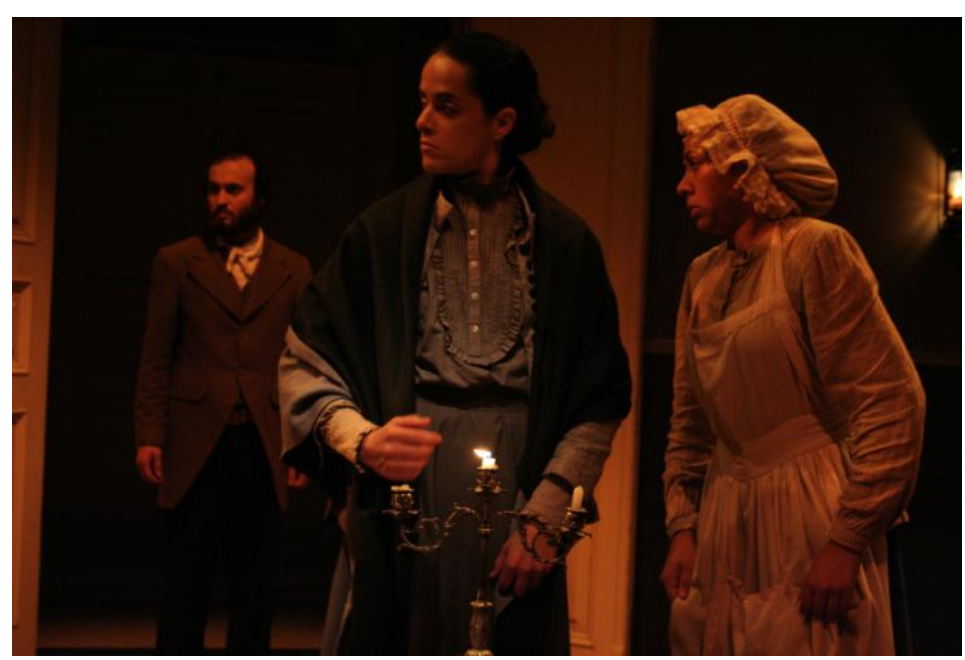

Figura 5 - Cena do Velório (Foto Myra Gonçalves)

Inês Alcaraz Marocco, Elisa Heidrich, Kalisy Cabeda, Philipe Philippsen, Rodrigo Fiatt, O Pulo do Gato ou Reflexões sobre a Presença do Ator

R.bras.est.pres., Porto Alegre, v.1, n.2, p. 312-330, jul./dez., 2011.

Disponível em http://www.seer.ufrgs.br/presenca 
Um outro tipo de trabalho na apropriação dos elementos foi feito nas cenas com o coro de mulheres, que corporificam o vento, elemento recorrente no romance, usadas como transição de cenas e modificação do cenário. A atuação das mulheres/vento surgiu a partir das improvisações da Máscara Neutra com o elemento da natureza, o $\operatorname{Ar}$ (Vento). Há, na obra de Erico Verissimo, uma grande simbologia sobre o Vento, presente inclusive no título da trilogia: O Tempo e o Vento, colocando-o como um personagem que afeta a vida das personagens. Neste caso, não há a utilização de qualquer impulso do elemento para a atuação, e sim a pura representação do elemento de forma imagética no corpo das atrizes do coro. A velocidade, a vibração, a força do vento estão presentes nos movimentos de seus corpos, impulsionados pela imaginação.

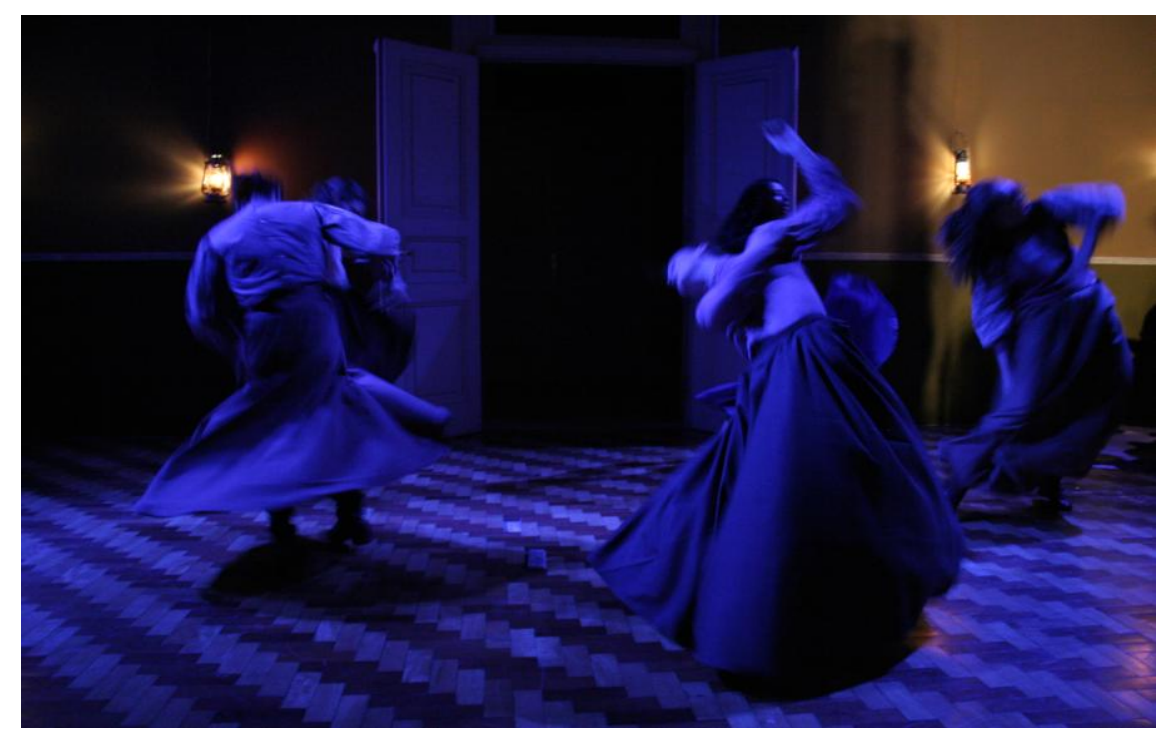

Figura 6 - Vento (Foto Myra Gonçalves)

O personagem Licurgo, por exemplo, é basicamente construído pelos elementos "terra e fogo", o que caracteriza bastante a sua força, brutalidade e vigor diante das situações apresentadas no texto. Esses elementos proporcionaram toda a carga dramática necessária para desencadear os conflitos existentes nas relações entre os personagens.

Inês Alcaraz Marocco, Elisa Heidrich, Kalisy Cabeda, Philipe Philippsen, Rodrigo Fiatt, O Pulo do Gato ou Reflexões sobre a Presença do Ator

R.bras.est.pres., Porto Alegre, v.1, n.2, p. 312-330, jul./dez., 2011.

Disponível em http://www.seer.ufrgs.br/presenca 


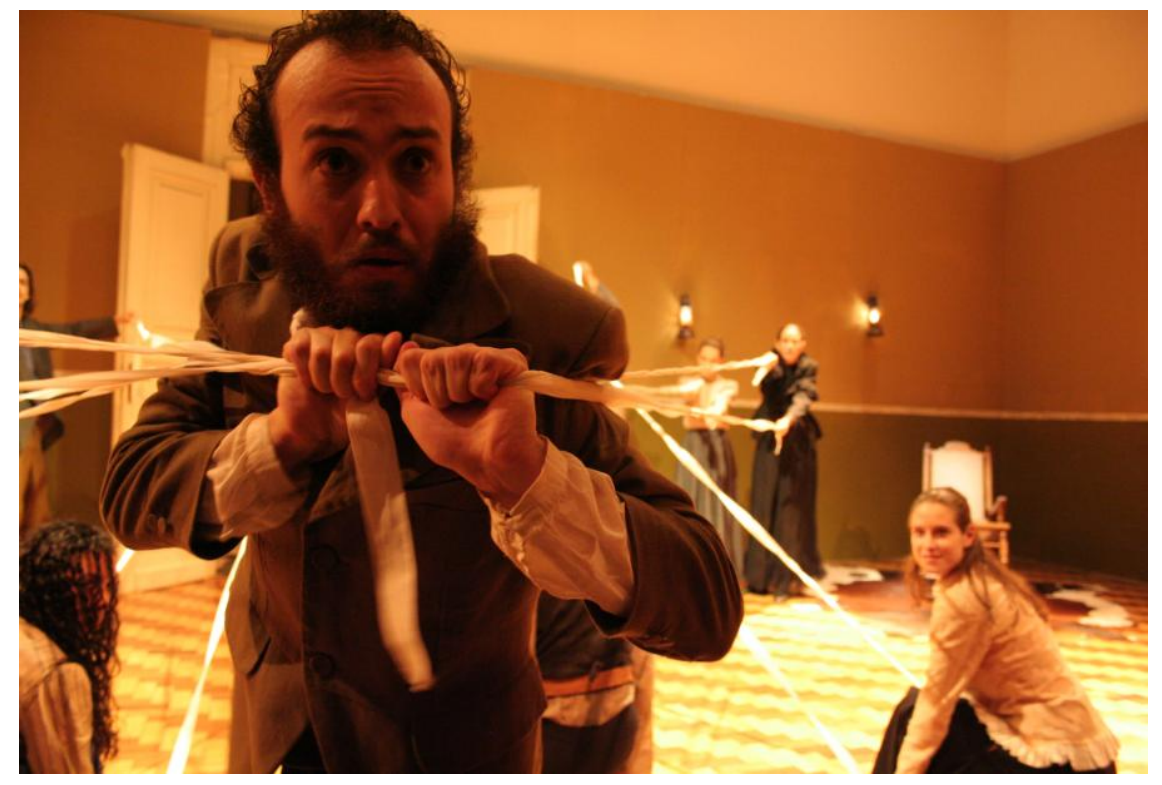

Figura 7 - Cena Xadrez (Foto Myra Gonçalves)

Além do trabalho com os elementos que favoreceram o desenvolvimento das energias necessárias na composição dos personagens e na instalação das atmosferas e climas da peça, é importante mencionar a imaginação que não só permeou todo o trabalho préexpressivo, mas também foi fundamental para a criação da dramaturgia. Seguindo a linha desenvolvida pela escola Lecoq, fundamentamos o trabalho da criação do espetáculo no desenvolvimento do imaginário no jogo, entendido como um "[...] ato essencialmente físico impondo a presença da vida pela ilusão" (Lecoq, 1987, p. 1). Neste trabalho,

[...] a ênfase é dada à visão poética, para desenvolver o imaginário criativo dos alunos. A dificuldade é não perder o essencial, e saber as dinâmicas da natureza e das relações humanas que constituem os motores da interpretação [...] (Lecoq, 1997, p. 153).

Antes mesmo de iniciar o processo de criação, na fase de preparação do elenco, realizamos exercícios denominados pré-jogos, atividades que desenvolvem um estado de prontidão, alerta, disponibilidade e sintonia de grupo. Após este primeiro momento, trabalhamos situações de jogo propriamente dito com exercícios que exploram a imaginação e a capacidade de ação/reação do

Inês Alcaraz Marocco, Elisa Heidrich, Kalisy Cabeda, Philipe Philippsen, Rodrigo Fiatt, O Pulo do Gato ou Reflexões sobre a Presença do Ator

R.bras.est.pres., Porto Alegre, v.1, n.2, p. 312-330, jul./dez., 2011.

Disponível em http://www.seer.ufrgs.br/presenca 
ator no aqui/agora. Para isso, foram feitas propostas para improvisar com poucos elementos: às vezes os atores eram desafiados a criar a partir de um único objeto em cena, outras vezes eles tinham como referência somente o lugar onde a situação criada deveria acontecer. Através dessas técnicas exercitamos a capacidade de ação/reação em situação de jogo, desenvolvendo no ator um estado psicofísico possibilitando-lhe uma autenticidade para o seu processo de criação. Ao iniciarmos o processo de criação da dramaturgia do espetáculo, mantivemos essa mesma linha de jogo, improvisando as cenas do romance, logo após a leitura delas, por exemplo. Outras vezes, fazíamos uma sequência das ações realizadas nas cenas e partíamos para a improvisação. O importante era manter o estado vivo do aquilagora. O romance já era rico em material para imaginarmos as situações e os personagens, o que tínhamos que fazer era transpô-los para a cena. Mas, além dele, nos cercamos de diferentes materiais durante todo o processo de criação.

O imaginário dos atores foi acionado também por diversos estímulos: imagens de quadros de Francisco Goya (1746-1828); objetos como tecidos, bancos, elásticos, caixa de objetos contendo materiais propostos pelo elenco como relativos ao universo da obra. Da mesma forma que estes estímulos acionaram o imaginário dos atores, as práticas do jogo teatral e da máscara neutra serviram como exercício constante para o treino do ator a enfrentar o vazio no seu trabalho diário de improvisação, estimulando o imaginário criativo do elenco constantemente durante o processo de criação. Na busca da presença física do ator, percebemos que estas duas técnicas permitem ao ator o vazio do não saber, o que possibilita estar presente para o jogo no aqui/agora, como o animal.

Dessa forma, através deste trabalho pré-expressivo, conseguimos resgatar a organicidade na atuação, assim como criar atmosferas e densidades dramáticas nas situações da peça. Podemos concluir então que o espetáculo $O$ Sobrado, apesar do elenco jovem e feminino em sua maioria, conseguiu, através deste trabalho com os atores e da transposição dos elementos

Inês Alcaraz Marocco, Elisa Heidrich, Kalisy Cabeda, Philipe Philippsen, Rodrigo Fiatt, O Pulo do Gato ou Reflexões sobre a Presença do Ator

R.bras.est.pres., Porto Alegre, v.1, n.2, p. 312-330, jul./dez., 2011.

Disponível em http://www.seer.ufrgs.br/presenca 
da natureza, criar um universo patriarcal, masculino e bélico.

\begin{abstract}
Notas
${ }^{1}$ A Etnocenologia é uma disciplina recente, criada em 1995 na Maison des Cultures $d u$ Monde em Paris por um grupo de pesquisadores entre os quais citamos: Jean Marie Pradier, Chérif Khaznadar, Jean Duvugnaud e Françoise Gründ, entre outros, e tem como princípio o estudo dos comportamentos espetaculares humanos organizados.

${ }^{2}$ Etologia é uma ciência que trata do estudo do comportamento social e individual dos animais e os costumes humanos como fatos sociais (Houaiss, 2001).

3 A máscara neutra foi criada por Jacques Copeau nos anos 20 na França como uma técnica para o trabalho do ator visando a desenvolver diversas capacidades, como, por exemplo, a neutralidade, o silêncio e a calma, de forma a propiciar ao ator desenvolver uma atitude. Com a técnica da máscara neutra, o ator desenvolve a atitude de alerta para o jogo e da mesma forma que o animal que está pronto para o ataque, é todo o seu corpo em sintonia que age. $\mathrm{O}$ rosto deixa de ser o ponto para onde convergem todas as expressões e o corpo na sua totalidade passa a ser fundamental, eliminando assim todos os estereótipos e vícios corporais e faciais. Ela se constitui na parte central do sistema pedagógico da escola de Jacques Lecoq. Ao portar a máscara neutra o ator se torna uma folha em branco onde se pode imprimir qualquer estilo de jogo.
\end{abstract}

\title{
Referências
}

BARBA, Eugenio. Le Canoë de Papier. Traité d`Anthropologie Théâtrale.

Bouffonneries, n. 28-29, p. 27-57, 1993.

BROOK, Peter. A Porta Aberta. Rio de Janeiro: Civilização Brasileira, 2000.

BROOK, Peter. Points de suspension: 44 ans d’exploration théâtrale 1946-1990. Paris: Seuil, 1992.

CARDONA, Patricia. La Agression Ritualizada I. Dramateatro Revista digital, 1999. Disponível em: <http://dramateatro.fundacite.arg.gov.ve/ojos_de_actor/agression_ritualizada.htm>. Acesso em: 15 fev. 2007.

FÉRAL, Josette. Dresser un Monument à I'Éphémère. Rencontres avec Ariane Mnouchkine. Paris: Editions théâtrales, 2001.

FÉRAL, Josette. Pourquoi l'Anthropologie Théâtrale?: entretien avec Nicola Savarese. In: Jeu - Revue de Théâtre, Montreal, n. 68, 1993. Disponível em: <http://id.erudit.org/iderudit/29274ac>. Acesso em: 20 jul. 2011.

HOUAISS, Antonio (Org.). Dicionário Houaiss da Língua Portuguesa. Rio de Janeiro: Ed Objetiva, 2001.

LEABHART, Thomas. A Máscara como Instrumento Xamânico no Treinamento Teatral de Jacques Copeau. Traduzido para fins exclusivamente didáticos por Marcelo Fagundes, 1994. Texto não publicado.

Inês Alcaraz Marocco, Elisa Heidrich, Kalisy Cabeda, Philipe Philippsen, Rodrigo Fiatt, O Pulo do Gato ou Reflexões sobre a Presença do Ator

R.bras.est.pres., Porto Alegre, v.1, n.2, p. 312-330, jul./dez., 2011.

Disponível em http://www.seer.ufrgs.br/presenca 
LECOQ, Jacques. O Corpo Poético: uma pedagogia da criação teatral/Jacques Lecoq. Com a colaboração de Jean-Gabriel Carasso e de Jean-Claude Lallias. Tradução de Marcelo Gomes. São Paulo: Editora Senac São Paulo, Edições SESC SP, 2010.

LECOQ, Jacques. Stages d’Été. Le jeu a travers les styles. Initiation Dramatique architecture et Théâtre, 1987. Programa da escola para os Estágios de verão de 15 a 31 de julho de 1987.

OIDA, Yoshi. com colab. Lorna Marshall. Um Ator Errante. São Paulo: Beca produções culturais, 1999.

PRADIER, Jean-Marie. Anatomie de l'Acteur. Revue Théâtre Public, n.76/77, p. 3544, jul./out. 1987.

PRADIER, Jean-Marie. Towards a Biological Theory of the Body in Performance. NTQ-New Theatre Quaterly, Cambridge, v. VI, n. 21, p. 86-98, fev. 1990.

PRADIER, Jean-Marie. Os Estudos Teatrais ou o Deserto Científico. Repertório Teatro e Dança, Salvador, ano 3, n. 4, p. 38-55, 2000.

SIEGFRIED, Walter. Emotion and Complexity. Revue Degrés, Bruxelas, ano 21, n. 7576, p. h-h8, automne/hiver, 1993.

TURNER, Victor. Body, Brain and Culture. In: TURNER, Victor. The Antropology of Performance. NY: PAJ ed.,1987/88. P. 156-179.

Inês Alcaraz Marocco é doutora em Esthétique Sciences et Technologie des Arts option Études Théâtrales et Chorégraphiques pela Université de Paris 8 Saint- Denis, Paris, França.Formação no Curso de Mime-Théâtre et Mouvement na École International Jacques Lecoq, Paris, França. Pesquisadora, diretora teatral e professora do Programa de Pós-graduação em Artes Cênicas da Universidade Federal do Rio Grande do Sul, em Porto Alegre.

E-mail: imarocco@terra.com.br

Elisa Beschorner Heidrich é mestranda do Programa de Pós-Graduação em Artes Cênicas da UFRGS. Formada em interpretação teatral na mesma Universidade, fez parte da pesquisa As técnicas corporais do gaúcho e sua relação com a performance do ator/dançarino orientada por Inês Alcaraz Marocco. Desenvolve seus trabalhos artísticos como atriz no grupo Depósito de Teatro e no grupo Cerco.

E-mail: elisa_heidrich@yahoo.com.br

Kalisy Cabeda é bacharel em Direção Teatral pela UFRGS, onde foi bolsista da FAPERGS na pesquisa As Técnicas Corporais do Gaúcho e sua Relação com a Performance do Ator/ Dançarino, orientada por Inês Marocco. Pesquisa as áreas de teatro e dança, a partir do seu trabalho no Grupo Cerco de teatro e como aluna do Grupo Experimental de Dança de Porto Alegre.

E-mail: kalisyr@yahoo.com.br

Philipe Philippsen é bacharel em Teatro, com habilitação em Interpretação Teatral pela UFRGS. Foi bolsista voluntário da pesquisa acadêmica As Técnicas Corporais do Gaúcho e a Sua Relação com a Performance do Ator-Dançarino sob orientação da

Inês Alcaraz Marocco, Elisa Heidrich, Kalisy Cabeda, Philipe Philippsen, Rodrigo Fiatt, O Pulo do Gato ou Reflexões sobre a Presença do Ator

R.bras.est.pres., Porto Alegre, v.1, n.2, p. 312-330, jul./dez., 2011.

Disponível em http://www.seer.ufrgs.br/presenca 
Prof $^{a} \operatorname{Dr}^{\mathrm{a}}$ Inês Marocco. Integrante do Grupo Cerco, responsável pela montagem de $O$ Sobrado, na qual trabalhou como ator e músico.

E-mail: philipefp@gmail.com

Rodrigo Fiatt é bacharel em Teatro com habilitação em Interpretação Teatral pela UFRGS. Foi bolsista PIBIC/CNPq da pesquisa As Técnicas Corporais do Gaúcho e sua Relação com a Performance do Ator/Dançarino, orientada pela Prof ${ }^{\mathrm{a}}$. Dra Inês Marocco. É integrante do Grupo Cerco, responsável pela montagem de O Sobrado, na qual foi, também, assistente de direção.

E-mail: rodrigofiatt@gmail.com

Recebido em Agosto de 2011

Aprovado em Novembro de 2011

Inês Alcaraz Marocco, Elisa Heidrich, Kalisy Cabeda, Philipe Philippsen, Rodrigo Fiatt, O Pulo do Gato ou Reflexões sobre a Presença do Ator

R.bras.est.pres., Porto Alegre, v.1, n.2, p. 312-330, jul./dez., 2011.

Disponível em http://www.seer.ufrgs.br/presenca 